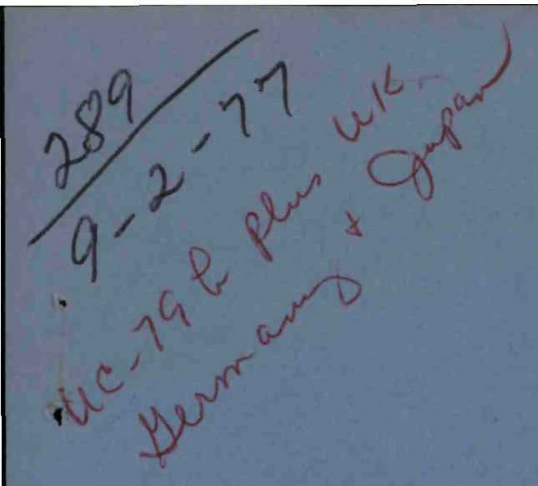

HEDL-TME 77-55

UC-79, b

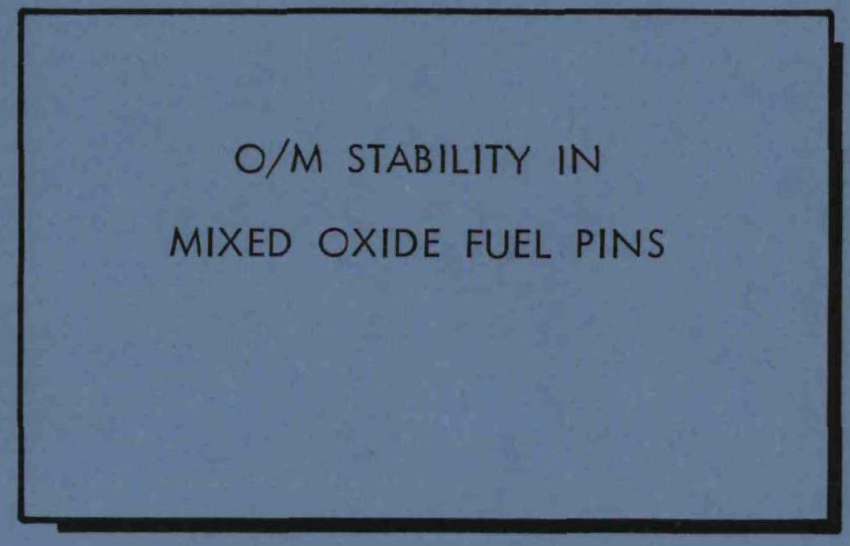

$e^{6}$

P.O. Box $1970 \quad$ Richland, WA 99352

HANFORD ENGINEERING DEVELOPMENT LABORATORY

Operated by Westinghouse Hanford Company

A Subsidiary of Westinghouse Electric Corporation

Prepared for the U.S. Energy Research and Development Administration under Contract No. EY-76-C-14-2170 


\section{DISCLAIMER}

Portions of this document may be illegible in electronic image products. Images are produced from the best available original document. 

HEDL-TME 77-55

UC-79, b

\section{O/M STABILITY IN}

MIXED OXIDE FUEL PINS

Gary Gottschalk

August 1977

NOTICE -

This report was prepared as an acroment. Nether

sponsored by the Unuted Stares United States Energy
the United States nor the Unien

Research and Development Administration, nontractors,

their employees, of their employees, makes any

subranty, express or implied, or assumes any legal

liabulty or responsibility for the accuracy, conplyes

or usefulness of any information, apparalus, prould not

process disclosed, or represents
infringe privately owned rights.

\section{Hanford Engineering Development Laboratory}

\begin{tabular}{lll}
\hline Operated by the & A Subsidiary of & for the United States \\
Westinghouse & Westinghouse Electric & Energy Research and \\
Corporation & Development Administration \\
Canford Company & & Contract No EY-76-C.14-2170 \\
\hline
\end{tabular}

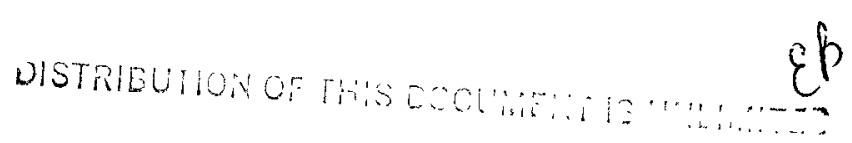


HEDL-TME 77-55

UC-79, b

\title{
O/M STABILITY IN MIXED OXIDE FUEL PINS
}

\author{
Gary Gottschalk
}

\section{ABSTRACT}

Mixed Oxide fuel pellets have been analyzed for change in oxygen to metal ratio following extended storage in FFTF fuel pins. 


.




\section{CONTENTS}

$\underline{\text { Page }}$

1.0 Introduction 1

2.0 Summary 1

3.0 Preparation of Fuel Pellets . 2

4.0 Fuel Pin Design and Loading Sequence 5

5.0 Results 5

6.0 Discussion of Results 6

6.1 Comparison of As-Loaded to After Storage Values 6

6.2 Comparison of Analytical to Theoretical Data 7

6.3 Analytical Precision for Determination of $0 / \mathrm{M}$

7.0 Conclusion $\quad 9$

$\begin{array}{lll}8.0 & \text { Acknowledgements } & 9\end{array}$

$\begin{array}{lll}9.0 & \text { References } & 9\end{array}$

\section{Appendices}

A: Fuel Processing Results and Procedure A-1

B: 0/M Analytical Data Following Storage B-1

\section{Figures}

1: Fuel Flow Diagram for 0/M Standard Fuel Pins 4

2: Fuel Column Design of 0/M Standard Pins 5

Tables

1: Chemical Properties of 0/M Standard Fuel Pellets 2

2: $0 / M$ Values of Source Pellets Used in Standard Pins 3

3: 0/M As-Loaded vs. 0/M After Storage 6

Distribution Distr-1 


\subsection{INTRODUCTION}

Fast Flux Test Facility (FFTF) driver fuel pins contain mixed oxide $\left(\mathrm{PuO}_{2}-\mathrm{UO}_{2}\right)$ fuel pellets. The atom ratio of oxygen-to-metal (0/M) in the fuel pellets is critical to fuel performance.

The oxygen-to-metal ratio $(0 / M)$ is determined by thermogravimetric analysis of fuel pellet samples taken at the time the pellets are loaded into fuel pins. The current specification limits for $0 / \mathrm{M}$ are 1.930 to 1.980 for individual pellets and 1.940 to 1.970 for the average of pellets within a pin.

Once loaded, fuel pins are stored for periods up to six years prior to use in the FFTF. It is necessary to verify the stability of the fuel $0 / M$ during storage in order to determine the actual $0 / \mathrm{M}$ at the time the fuel is inserted into the FFTF. No nondestructive technique with sufficient accuracy is currently available for the determination of $0 / M$ in sealed fuel pins.

A series of typical FFTF driver fuel pins was prepared to monitor the $0 / M$ during long-term storage and for use as standards in development of nondestructive techniques for measuring $0 / M$ in sealed fuel pins. For this experiment, fuel pellets were removed from sealed vendor qualification pins, thermally processed as three distinct groups to produce new 0/M's ranging from 1.930 to 2.0035 . These fuel pellets were then loaded into new pins, which were stored for over 2.5 years, after which time they were removed and analyzed for any change in $0 / M$ ratio.

\subsection{SUMMARY}

No significant change in the $0 / M$ ratio occurred during storage. This is in agreement with the theoretical analysis. The implication of this analysis is that the $0 / M$ of mixed oxide fuel at the time of insertion into FFTF does not differ significantly from the value at the time of fuel pin loading. 


\subsection{PREPARATION OF FUEL PELLETS}

The fuel pellets were obtained from commercially-produced qual ification fuel pins with pellets of relatively high 0/M (1.9585). To insure pelletto-pellet homogeneity, pellets from selected sintering batches in one fuel pellet lot were used. The identity of the sintering batch was maintained throughout the experiment. Chemical and physical characteristics of the fuel pellets are presented in Table 1 .

\section{TABLE 1}

CHEMICAL PROPERTIES OF O/M STANDARD FUEL PELLETS

Characteristic

Moisture Content

Gas Content

Planer Smear Density

Pellet Fissile

Uranium

Plutonium

Isotopic $\left(\mathrm{Pu}^{239}+\mathrm{Pu}^{241}\right)$

Pellet Weight/Length

Diameter
Lot Mean

$<5 \mathrm{ppm}$

$.0429 \mathrm{cc} / \mathrm{gram}$

86. 109\% Theoretical

.8439 grams/gram

$68.50 \%$

.1983 grams/gram

$88.063 \%$

4.834 grams/inch

.1940 inches
Lot Standard Deviation

$0 \mathrm{ppm}$ $.0098 \mathrm{cc} / \mathrm{gm}$ $.6475 \%$ Theoretical .0057 grams/gram $.1127 \%$

.00035 grams/gram $.0424 \%$

.030 grams/inch .0004 inches

Pins containing pellets from the selected fuel pellet lot were initially evaluated during receiving inspection in 1973.

In July, 1974, 12 fuel pins from the selected fuel pellet lot were cut open. The pellets were removed and stored under a rough vacumm of 23 inches (Ref.1). Storage times ranged from 15 to 30 days. Samples were submitted for analysis immediately upon pin down-loading and data is presented in Table 2. Elapsed time between removal of pellets from pins and thermogravimetric analysis was less than three hours. During that interval, the 
pellets were sealed in plastic bags filled with gas of $99.9 \%$ purity. Past experience has shown $0 / \mathrm{M}$ drift under those conditions to be negligible (or $<.002$ 0/M units) and thus has no impact on the study.

TABLE 2

O/M VALUES OF SOURCE PELLETS USED IN STANDARD PINS

$\begin{array}{lr}1.966 & 1.956 \\ 1.961 & 1.950 \\ 1.964 & 1.959 \\ 1.955 & 1.957 \\ 1.955 & 1.959 \\ 1.955 & 1.965 \\ 1.955 & 1.951 \\ 1.961 & 1.958 \\ 1.962 & 1.963 \\ 1.964 & 1.957 \\ 1.967 & 1.959 \\ 1.959 & 1.953 \\ 1.950 & 1.965 \\ 1.959 & 1.955 \\ 1.950 & \times 1.9585 \\ 1.966 & 0 \\ & .0051\end{array}$

The experiment called for three groups of pellets, each at a different $0 / M$ level. Group 1 was processed through two reduction cycles to an $0 / M$ of 1.932. Group 3 was processed through an oxidation cycle to an $0 / \mathrm{M}$ of 2.000 . Group 2 was not processed, providing pellets with an 0/M of 1.959. The fuel process flow and resulting $0 / M$ values are summarized in Figure 1. Detailed processing records for groups 1,2, and 3 are presented in Appendix A. 


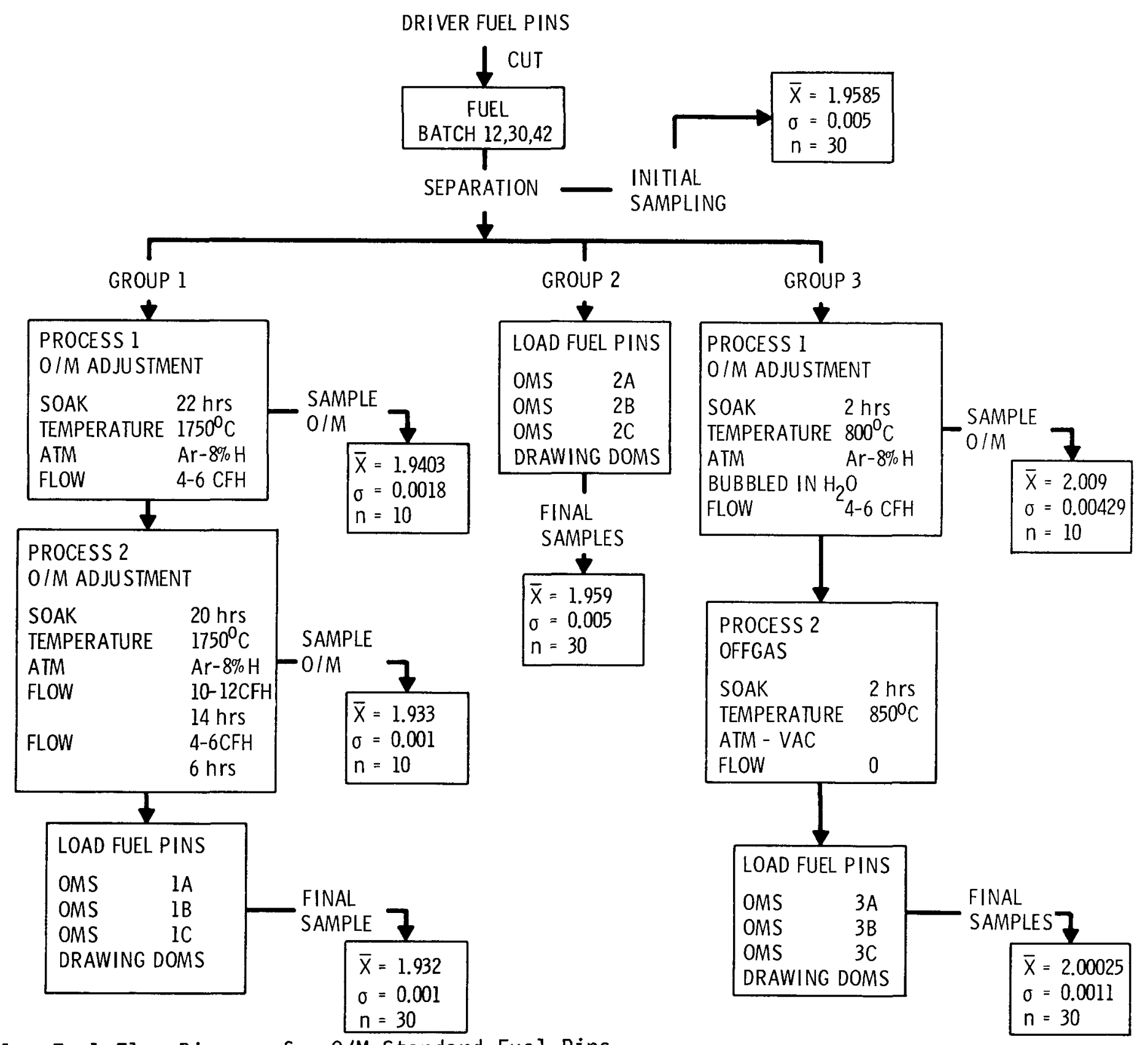

FIGURE 1. Fuel Flow Diagram for O/M Standard Fuel Pins. 


\subsection{FUEL PIN DESIGN AND LOADING SEQUENCE}

The pin design used was standard FFTF design. The standard design was used to assure the same plenum to fuel ratio as the driver fuel pin. The fuel column was designed to be consistent with a driver pin and to maintain the sintering batch identity of all fuel pellets. The reference weights and lengths for each batch are given in Figure 2. The three batches used were labeled 12,30 and 42 . Batch 23 was a mixture of pellets from the three independent batches.

\begin{tabular}{|c|c|c|c|}
\hline BATCH 23 & BATCH 42 & BATCH 30 & BATCH 12 \\
\hline & & & \\
\hline $30.2 \mathrm{~g}$ & $12.3^{\prime \prime} \longrightarrow 8.7^{\prime \prime} \longrightarrow$ & $8.7^{\prime \prime} \longrightarrow$ LENGTH \\
WEIGHT
\end{tabular}

FIGURE 2. Fuel Column Design of O/M Standard Pins (All Values are Reference).

The fuel pellets were submitted to the lab for analysis simultaneously with the transfer of the fuel pins to the closure welding chamber. $0 / M$ analytical results at the time of loading are included in Appendix $A$. Three pins from each $0 / M$ group were loaded, making a total of nine pins.

\subsection{RESULTS}

In February 1977, one fuel pin from each group was cut open and sample pellets analyzed for $0 / M$, gas content and moisture content. Samples for $0 / M$ analysis were submitted to the $1 a b$ within one hour of pin opening. A summary of the $0 / M$ values after storage versus the $0 / M$ values at the time of loading is presented in Table 3. Detailed $0 / M$ analytical results after storage are provided in Appendix B. 


\subsection{DISCUSSION OF RESULTS}

\subsection{Comparison of As-Loaded to After Storage Values}

Each batch within each group was analyzed for significant change in 0/M using the Fischer $\tau$ test. Only the after storage values for Batch 12, Group 1 showed a significant difference from the as-loaded values.

\section{TABLE 3}

O/M AS-LOADED vS. O/M AFTER STORAGE

\begin{tabular}{|c|c|c|c|c|c|}
\hline \multirow[b]{2}{*}{ Groups } & \multirow[b]{2}{*}{ Batch } & \multicolumn{2}{|c|}{ As-Loaded } & \multicolumn{2}{|c|}{ After Storage } \\
\hline & & $\underline{\bar{X}} 0 / \mathrm{M}$ & $0 \quad 0 / M$ & $\underline{\bar{X}} 0 / \mathrm{M}$ & $\underline{00 / M}$ \\
\hline \multirow[t]{4}{*}{1} & 12 & 1.9321 & .0005 & 1.935 & .00094 \\
\hline & 30 & 1.9316 & .0005 & 1.9307 & .00189 \\
\hline & 42 & 1.9335 & .0005 & 1.931 & .00275 \\
\hline & Combined & 1.9324 & .0009 & 1.9322 & .00277 \\
\hline \multirow[t]{4}{*}{2} & 12 & 1.9585 & .0027 & 1.9577 & .00254 \\
\hline & 30 & 1.9580 & .0065 & 1.9589 & .00608 \\
\hline & 42 & 1.9591 & .0057 & 1.9609 & .00387 \\
\hline & Combined & 1.9585 & .0051 & 1.9592 & .00446 \\
\hline \multirow[t]{4}{*}{3} & 12 & 2.0017 & .0008 & 2.0025 & .00127 \\
\hline & 30 & 2.0042 & .0019 & 2.0054 & .00419 \\
\hline & 42 & 2.0036 & .0029 & 2.0029 & .00418 \\
\hline & Combined & 2.0035 & .0024 & 2.0035 & .00361 \\
\hline
\end{tabular}

The combined totals for all batches in each group showed no significant difference from the as-loaded values ( $\tau$ test for equality of means $p=.01$ ). 


\subsection{Comparison of Analytical to Theoretical Data}

The theoretical limit for $0 / M$ change has been calculated assuming that all free oxygen in the fuel pin will be absorbed by the fuel. The credible oxygen sources were considered to be water trapped in the fuel at a level of $50 \mathrm{ppm}$, and oxygen in the bonding gas at a maximum level of $0.1 \%$. The change in $0 / M$ due to the total credible oxygen sources was calculated as follows:

1) The total gas volume of an empty fuel pin was calculated from the equation

$$
\begin{aligned}
& \text { (length) } \times \pi \times\left(\frac{\text { Diameter }}{2}\right)^{2}=\text { total gas volume } \\
& \text { total gas volume }=2.889 \mathrm{in}^{3}
\end{aligned}
$$

2) The volume of the individual components was calculated as follows:

- maximum spring volume determined from specification

max. spring volume $=.005 \mathrm{in}^{3}$

- the spacer, volume was calculated from the formula:

length $\times \pi \times\left[\left(\frac{\max \cdot 0 \mathrm{D}}{2}\right)^{2}-\left(\frac{\min \cdot \mathrm{ID}}{2}\right)^{2}\right]$

$\max$. spacer volume $=.061 \mathrm{in}^{3}$

- the fuel and insulator stack volume was calculated by the following equation:

length $x \pi \times\left(\frac{\mathrm{Dia} \cdot}{2}\right)^{2}=$ stack volume

stack volume $=1.0071 \mathrm{in}^{3}$ 
3) The net plenum volume was calculated as follows:

net plenum volume $=$ total gas volume - (spring volume + spacer volume + stack volume)

net plenum volume $=1.76 \mathrm{in}^{3}=30 \mathrm{cc}$

4) From the net plenum volume and the gas specification of $0.1 \% \max$. impurities, the maximum amount of $\mathrm{O}_{2}$ available can be calculated by:

Vol. $0_{2}=30 \mathrm{cc} \times .001=.03 \mathrm{cc} 0_{2}=3 \times 10^{-5}$ 1iters $0_{2}$

5) The total moles of $\mathrm{O}_{2}$ available is then calculated by:

$\frac{3 \times 10^{-5} \text { liters }}{22.4 \text { liters } / \text { mole }}=1.34 \times 10^{-6}$ moles

6) The maximum amount of $\mathrm{O}_{2}$ available from moisture in the fuel is calculated as follows:

$(172 \mathrm{~g})\left(\frac{30 \mathrm{ppm} \max \cdot \mathrm{H}_{2} \mathrm{wt} \%}{32 \mathrm{~g} \mathrm{O}_{2} / \text { mole } \mathrm{O}_{2}}\right)\left(\frac{16 \mathrm{~g} \mathrm{O}_{2}}{18 \mathrm{~g} \mathrm{H}_{2} \mathrm{O}}\right)=1.43 \times 10^{-4}$ moles $\mathrm{O}_{2}$

7) The total nominal moles of $\mathrm{O}_{2}$ in the fuel is determined as follows:

$$
\frac{(172 \mathrm{~g} \mathrm{fuel})\left(.12 \mathrm{wt} \% \mathrm{O}_{2}\right)}{32 \mathrm{~g} 0_{2} / \text { mole } 0_{2}}=.645 \text { moles } 0_{2}
$$

8) The maximum change due to credible sources of oxygen is then calculated by:

$\frac{\left(1.44 \times 10^{-4} \text { available moles } 0_{2}\right)}{.645 \text { total moles } 0_{2}} \times 100=2.232 \times 10^{-2} \%$ change

This corresponds to an $0 / M$ change of $.00050 / M$ units. 


\subsection{Analytical Precision for Determination of $0 / M$}

The analytical precision was determined from Quality Control Samples run during the periods of the analysis. During both periods the precision was determined to be approximately .0023 0/M units (1 o).

\subsection{CONCLUSION}

The $0 / M$ ratio of mixed oxide fuel pins does not change significantly when sealed in finished fuel pins.

\subsection{ACKNOWLEDGEMENTS}

To the technicians of Component Systems Acceptance for their fine work in fabrication, testing, and evaluating the standard fuel pins.

To H. G. Powers and L. H. Rice for their management guidance and encouragement.

To M. C. Burt for his aid in scheduling the $0 / M$ samples in the analytical Tab.

\subsection{REFERENCE}

"Control and Behavior of $0 / M$ and Offgas During Fabrication of Mixed Oxide $\left(\mathrm{U}_{0} .75-\mathrm{Pu}_{0.25}\right)-\mathrm{x}$ for HEDL Irradiation Testing." HEDL-TME 72-125 Drawing H-4-20581. 
APPENDIX A

FUEL PROCESSING RESULTS AND PROCEDURE

Group 1

Determined by 30 samples, the standard deviation was .00093 . Listed below are the fuel $0 / M$ values obtained from Group 1 pellets. Also listed are the data obtained from sampling immediately following the sintering runs to adjust the $0 / M$.

Final Samples (Taken at Loading Time)

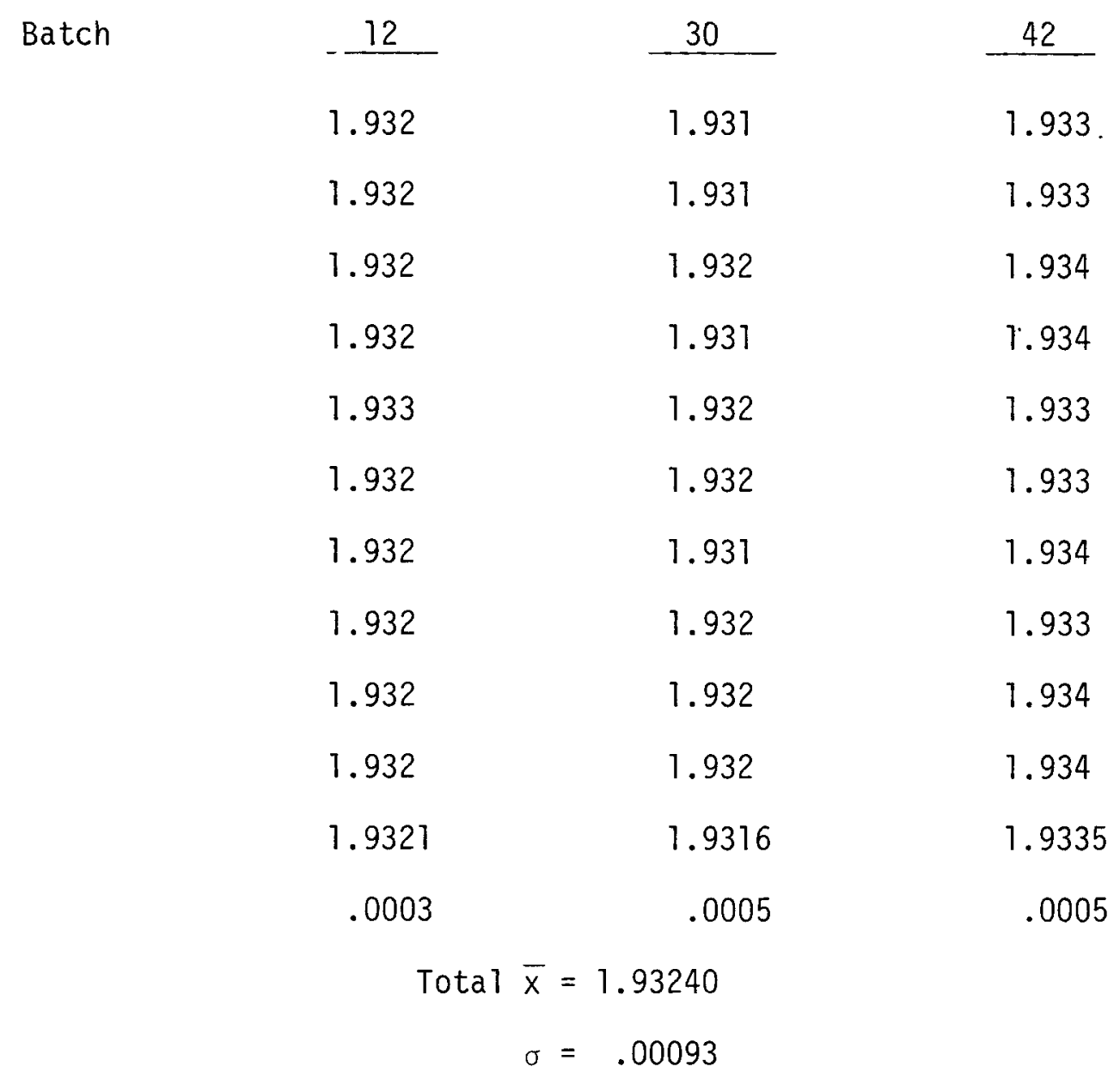




\section{Samples Taken Following Furnace Process}

\begin{tabular}{|c|c|c|}
\hline Furnace Run 1 & & Furnace Run 2 \\
\hline $1750^{\circ}$ & & $1750^{\circ}$ \\
\hline 4-6 CFH, $20 \mathrm{hr}$. & & $\begin{array}{l}\text { - 12-14 CFH (est.) } 12 \mathrm{hr} \text {. gas flow } \\
\text { - 4-6 CFH, } 6 \mathrm{hr} \text {. }\end{array}$ \\
\hline 1.939 & & $1.932-$ \\
\hline 1.939 & & 1.934 \\
\hline 1.939 & & 1.933 \\
\hline 1.940 & & 1.934 \\
\hline 1.939 & & 1.931 \\
\hline 1.939 & & 1.934 \\
\hline 1.940 & & 1.934 \\
\hline 1.943 & & 7.931 \\
\hline 1.944 & & 1.943 \\
\hline 1.941 & & 1.932 \\
\hline 1.9403 & $\bar{x}$ & 1.9329 \\
\hline .0018 & $\sigma$ & .0013 \\
\hline
\end{tabular}

\section{Processing Procedure}

A furnace basket diagram was used for batch integrity.

Furnace Run 1. The process times were as listed below:

1) $6 \mathrm{hr} .-$-heat furnace to $1750^{\circ}--$ atmosphere Argon-8\% Hydrogen

2) $22 \mathrm{hr} .--$ soak $1750^{\circ}-$-atmosphere Argon-8\% Hydrogen 6-8 CFH 
3) $1-1 / 2 \mathrm{hr} .--\cos 1$ to $1200-1400^{\circ}$

4) $42 \mathrm{hr} .--\operatorname{cool}$ to room temperature, and store atmosphere-vacuum

5) 10 pellets samples for $0 / \mathrm{M}$--result $\bar{x}=1.9403 \quad \sigma=.0018$

6) All pellets transferred to vacuum canister for storage.

Furnace Run 2. The process times were as listed below:

1) $6 \mathrm{hr}$.--heat furnace to $1750^{\circ} \mathrm{C}--$ atmosphere Argon- $8 \%$ Hydrogen

2) $14 \mathrm{hr} .-$-soak $1750^{\circ} \mathrm{C}$--atmosphere Argon-8\% Hydrogen rate 12-14 $\mathrm{CFH}$ (estimate)

3) $6 \mathrm{hr}$.--soak $1750^{\circ} \mathrm{C}$--atmosphere Argon-8\% Hydrogen rate 4-6 CFH

4) $1-1 / 2 \mathrm{hr} .--\operatorname{coo} 1$ to $1200-1400^{\circ} \mathrm{C}--$ atmosphere Argon- $8 \%$ Hydrogen rate 4-6 CFH

5) $14 \mathrm{hr} .--\operatorname{cool}$ to room temperature and store atmosphere--vacuum

6) 10 pellets samples for $0 / M--$ result $\bar{x}=1.9329 \quad \sigma=.0013$

7) All pellets transferred to vacuum canister for storage.

10 samples from each independent batch (30 total) were sampled. The results are listed in Table 1. The fuel pin final welds were made simultaneously with the analysis of the samples.

Group 2

No processing was done to Group 2 other than sampling and loading into fuel pins. 
The results of sampling at loading time are listed below. The fuel pin final closure welds were made simultaneously with the sample analysis.

\section{Samples As Loaded}

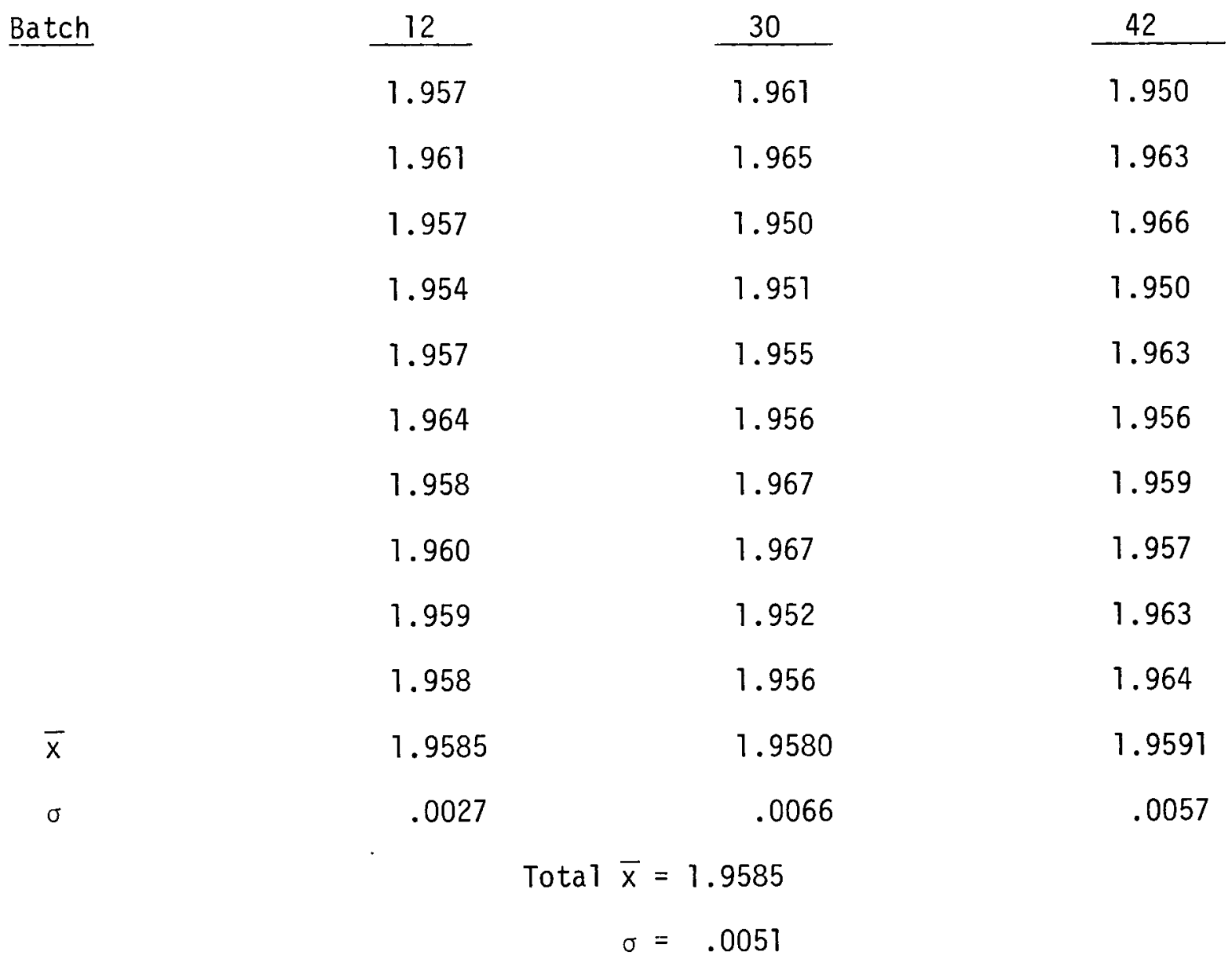

Group 3

Processing Procedure

A furnace basket diagram was used to maintain batch identity. The soak was at $800^{\circ} \mathrm{C}$ for 2 hours with $\mathrm{AR}-8 \% \mathrm{H}$ passed through a $\mathrm{H}_{2} \mathrm{O}$ bubbler to provide the oxidizing agent. 
The $0 / M$ of ten samples taken following the $0 / M$ adjustment run is 1 isted below.

Samples Taken Following 0/M Adjustment

$$
\begin{array}{cc}
800^{\circ} \mathrm{F}-\text { Soak } 2 \mathrm{hr} .-\mathrm{atm} \mathrm{Ar}-8 \% & \mathrm{H}--\mathrm{H}_{2} \mathrm{O} \text { bubbler } \\
2.004 & 2.009 \\
2.016 & 2.009 \\
2.008 & 2.010 \\
2.007 & 2.016 \\
2.008 & 2.003 \\
\bar{x}=2.009 & \\
\sigma=.00429 & \\
\mathrm{n}=10
\end{array}
$$

Ten samples from each independent batch (30 total) were sampled. The fuel pin final welds were made simultaneous with the analysis of the samples. The results of sample taken at loading time are listed below.

Final Samples (Taken at Loading Time) Group 3

Batch

\begin{tabular}{lll}
12 & 30 & 42 \\
\cline { 2 - 3 } 2.001 & 2.005 & 2.004 \\
2.003 & 2.005 & 2.003 \\
2.001 & 2.005 & 2.001 \\
2.001 & 2.002 & 2.003 \\
2.001 & 2.002 & 2.003 \\
2.003 & 2.003 & 2.008 \\
2.002 & 2.007 & 2.004 \\
2.001 & 2.004 & 2.006 \\
2.002 & 2.002 & 2.003 \\
2.002 & 2.007 & 2.011
\end{tabular}


Final Samples (Taken at Loading Time) Group 3 (cont'd)

\begin{tabular}{|c|c|c|c|}
\hline Batch & 12 & 30 & 42 \\
\hline $\bar{x}$ & 2.0007 & 2.0042 & 2.0046 \\
\hline$\sigma$ & .0008 & .0019 & .0029 \\
\hline$n$ & $n=10$ & $n=10$ & $n=10$ \\
\hline \multicolumn{4}{|c|}{ Total $\bar{x}=<2.00035$} \\
\hline
\end{tabular}




\section{APPENDIX B}

O/M ANALYTICAL DATA FOLLOWING STORAGE

Group 1: Pin OMS IC

Batch

Sample 1

2

3

4

5

6

7

8

9

10

$\bar{x}$

$\sigma$
12

1.934

1.937

1.935

1.934

1.936

1.935

1.935

1.935

1.934

1.935

1.935

.00094

30

1.928

1.930

1.933

1.930

1.931

1.929

1.931

1.934

1.929

1.932

1.9307

.00189
42

1.931

1.932

1.933

1.930

1.931

1.937

1.928

1.927

1.931

1.930

1.931

.00295
Total
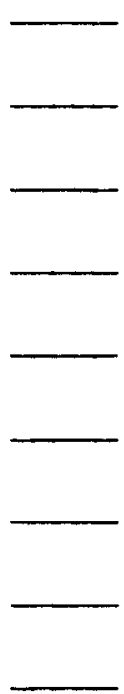

1.9322

.00277

Group 2: Pin OMS 2C

Batch

Sample 1

2

3

4

5

6

7

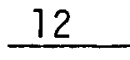

1.961

1.955

1.960

1.955

1.957

1.961

1.957
30

1.955

1.961

1.951

1.967

1.957

1.967

1.953
42

1.961

1.961

1.957

1.958

1.966

1.961

1.967

Total
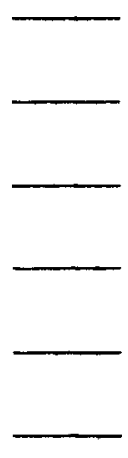


$\begin{array}{ccccc}8 & 1.954 & 1.963 & 1.955 & - \\ 9 & 1.959 & 1.963 & 1.964 & - \\ 10 & 1.958 & 1.952 & 1.959 & 1.9592 \\ \bar{x} & 1.9577 & 1.9589 & 1.9609 & .00277 \\ \sigma & .00094 & .00189 & .00295 & .00446\end{array}$

Group 3: Pin OMS 3C

\begin{tabular}{|c|c|c|c|c|}
\hline Batch & 12 & 30 & 42 & Total \\
\hline Sample 1 & 2.001 & 2.003 & 2.001 & \\
\hline 2 & 2.003 & 2.004 & 2.002 & \\
\hline 3 & 2.002 & 2.009 & 2.006 & \\
\hline 4 & 2.002 & 2.003 & 2.000 & \\
\hline 5 & 2.002 & 2.007 & 1.999 & \\
\hline 6 & 2.005 & 2.015 & 2.013 & \\
\hline 7 & 2.003 & 2.000 & 2.005 & \\
\hline 8 & 2.002 & 2.003 & 2.000 & \\
\hline 9 & 2.004 & 2.004 & 2.001 & \\
\hline 10 & 2.001 & 2.006 & 2.002 & \\
\hline $\bar{x}$ & 2.0025 & 2.0054 & 2.0029 & 2.0035 \\
\hline$\sigma$ & .00127 & .00419 & .00418 & .00361 \\
\hline
\end{tabular}


DISTRIBUTION

UC-79 (251)

UC-79, b (38)

ERDA-RL (2)

Manager

Patent Chief

$\underline{\text { FFTF-PO }} \quad(5)$

Director

ERDA-RDD-HDQ

Director, Program Division

HEDL (31)

D. W. Bennett W/FED

T. T. Claudson $W / C-15$

R. E. Dahl $W / C-20$

C. K. Day W/A-132

D. S. Dutt $\quad W / C-21$

E. A. Evans $\quad W / C-16$

E. M. Greyback $W / C-18$

G. P. Gottschalk W/C-18 (2)

E. N. Heck W/

J. E. Irwin W/

W. R. Jentzen $W / C-19$

R. D. Leggert $W / C-21$

R. B. McCord $W / C-19$

B. J. Miller $\quad W / C-24$

D. H. Nyman W/A-36

H. G. Powers $W / C-10$

D. E. Rasmussen $W / C-130$

J. D. Watrous W/A-105

Central Files (10)

Technical Publication 